\title{
Displays of parent suitability in adoption assessment reports
}

J udith Lind and Cecilia Lindgren

The self-archived postprint version of this journal article is available at Linköping University Institutional Repository (DiVA):

http:// urn.kb.se/ resolve?urn=urn:nbn:se:liu:diva- 129380

N.B.: When citing this work, cite the original publication.

Lind, J., Lindgren, C., (2017), Displays of parent suitability in adoption assessment reports, Child \& Family Social Work, 22(51), 53-63. https:// doi.org/ 10.1111/ cfs.12305

Original publication available at:

https:// doi.org/ 10.1111/cfs.12305

Copyright: Wiley

http:// eu.wiley.com/WileyCDA/ 


\section{TITLE PAGE}

\section{Title:}

Displays of parent suitability in adoption assessment reports

\section{Running head:}

Displays of parent suitability

\section{Authors in alphabetical order:}

Judith Lind

$\mathrm{PhD}$, Senior lecturer

Department of Thematic Studies - Child studies

Linköping University

58183 Linköping

SWEDEN

+4613282901

judith.lind@liu.se

Cecilia Lindgren (corresponding author)

$\mathrm{PhD}$, Senior lecturer

Department of Thematic Studies - Child studies

Linköping University

58183 Linköping

SWEDEN

+4613282927

cecilia.lindgren@liu.se 


\title{
Displays of parent suitability in adoption assessment reports
}

\begin{abstract}
Through adoption, the state actively contributes to creating families. It therefore also assumes the role of guarantor of the child's best interests in the adoption process, which entails assessing the suitability of presumptive adoptive parents. In the present article, we use the concluding sections of assessment reports on applicants for intercountry adoption in Sweden to answer the following question: What must be said about an individual or a couple in order for her/them to be seen as a suitable adoptive parent? We thus assume that report conclusions serve to display parent suitability to their audiences. The assessment aligns with Swedish national adoption guidelines, and the study shows how the assessment handbook comes to serve as a catalogue of arguments that not only define good parenthood, but also outline a way of life that is suitable for parenthood. The analysis illustrates how valid arguments for granting consent to adopt refer to three layers of suitability. They include not only the applicants' insights into and knowledge about adoption in particular and children in general, but also their conventional and orderly life, i.e. a life free from distractions that could hinder a wholehearted focus on children and family life.
\end{abstract}

Keywords (5): adoption, assessment, display, home study, parent suitability

\section{Introduction}

Through adoption, the state actively contributes to creating families. It therefore also assumes the role of guarantor of the child's best interests in the adoption process, which entails assessing the suitability of presumptive adoptive parents. In contrast to evaluations of parents' performances in child protection cases, adoption assessments concern the parenting potential of individuals who hope to become parents to an as yet unknown child (Lind 2008; Noordegraaf et al. 2008a). The results of such assessments are summarized in an assessment report (or 'home study report'), which also includes the social worker's statement on the applicants' suitability as parents. In the present article, we concentrate on the assessment of applicants for intercountry adoption in Sweden who have been granted consent to adopt. We use the concluding sections of assessment reports to answer the following question: What must be said about an individual or a couple in order for her/them to be seen as a suitable adoptive parent?

In Sweden, three non-governmental organizations are authorized by the Family Law and Parental Support Authority to intermediate intercountry adoptions. Children are adopted from approximately 30 countries, the most common being China, Taiwan, South Korea, South Africa and Colombia. Any person or couple who wish to adopt must apply to the social welfare committee in the municipality where they live. After adoption applicants have completed a mandatory preparation course, their suitability as adoptive parents is assessed by an assigned social worker who performs register checks (social services and criminal records) and conducts interviews and home visits. The written report, including the social worker's recommendation, is forwarded to the municipal social welfare committee, which then takes the formal decision on whether or not to grant the applicants consent to adopt (National Board of Health and Welfare (hereafter NBHW) 2009). 
In its capacity as a document on which the municipal social welfare committee is to base its decision, the assessment report serves a certain institutional purpose (Hall et al. 2006; Hydén 1997; Noordegraaf et al. 2009). The report is supposed to support the social worker's recommendation to the committee and hence, in recommending that the committee grants consent, it must display the applicants' suitability as adoptive parents. In family sociology, the concept of display was first coined by Janet Finch (2007). Displays of families, according to Finch, serve to confirm certain actions as family actions and certain relationships as family relationships (Finch 2007). The concept has later been used in relation to parenthood, acknowledging that parents, especially mothers, to some extent regard parenting activities as displays of their parenthood - displays on the basis of which their qualities as a parent are judged by other parents and professionals (Harman \& Cappellini 2015; see also Caputo 2007). Hence, a vital element of display is the audience in front of which it occurs (Dermott \& Seymour 2011; Finch 2007).

During the adoption assessment process, displays of good parenthood, or rather of parent suitability, occur at several stages. During interviews with the social worker, applicants may be expected to display their own suitability by telling certain things about themselves and omitting others (cf. Noordegraaf et al. 2008b, 2010). The social worker, in turn, must display the suitability of applicants whom s/he recommends be granted consent to adopt in the report, which will be read by the municipal social welfare committee (cf. Noordegraaf et al. 2008a). At the final stage of the process, the assessment report serves as a presentation of the approved applicants to an adoption authority or other representatives of the child in a sending country (NBHW 2009). With these readers of the report in mind, adoption agencies in Sweden urge social workers to omit unnecessary compromising information about the applicants, such as “... not so flattering information about a relative, some sort of faux pas in adolescence or passing difficulties during the school years”, thus allowing applicants to be presented as favourably as possible (Barnens Vänner 2014).

In his article on adoption assessments of lesbian couples, Hicks (2000) shows how social workers strove to present the same-sex relationships of applicants whom they wanted to see approved by the adoption panel in such a manner that the relationships would be acceptable to the panel. Hicks refers to this strategy as social workers "playing the panel game” (p. 161). Hence, rather than a documentation of the assessment process in its entirety, the report can be viewed as a display of the applicants' suitability. In a study of child protection cases, Holland (1999) found that some social workers referred to their decisions as judgments that had gradually emerged during the assessment, not seldom attributed to their gut feelings about the case. In their reports, however, and when they needed to present their decisions to the court, their managers or the family, the social workers claimed to use a discourse of and refer to methods of scientific observation. One social worker explained this process by stating that she would seek evidence to underpin the conclusions and recommendations she felt were appropriate, as they would otherwise appear weak and be challenged. The question, then, is how the social worker can be certain about what constitutes valid evidence. For any Swedish social worker operating in a similar manner in adoption assessments, there is a simple answer to that question: S/he consults the adoption assessment handbook (hereafter the handbook, NBHW 2009).

The topics that should be covered in an adoption assessment are specified in the Social Services Act and include “the applicant's knowledge about and insight concerning adopted children and their needs and the implications of the planned adoption, as well as the applicant's age, state of health, personal qualities and social network" (quoted in NBHW 
2009, p. 47). When it was first published (in 2008 in Swedish and translated into English in 2009), the handbook served as a response to critique against the widely varying assessment practices in different municipalities by defining areas of inquiry and suggesting questions to be asked by the social worker. Its content is structured under the following headlines: 'The applicants' knowledge, insight and readiness to meet the needs of an adoptive child', 'Applicants' parenting capacity' and 'Resources in terms of the applicants' relationship, social network and environment'. It also defines, however, what constitutes resources and risk factors. Every section of the handbook ends with a bulleted list of "examples of factors which indicate - or might indicate - that the applicants would not be suitable adopters" (NBHW 2009, p. 58). Among the more than 70 factors mentioned are, for example, set expectations about the child, insufficient empathy, problems coping with difficulties and crises, lack of balance in the relationship and no close friends. The handbook does not, however, prescribe a certain method. Instead, it notes the lack of an established assessment method and focuses more on methods for gathering information about the applicants.

The handbook prescribes that the assessment report be concluded with "the social worker's analysis and conclusions" about the applicants' suitability as adoptive parents (NBHW 2009, p. 106). This concluding analysis should take into account "all the aspects which are relevant for gauging their parenting capacity" and should include resources as well as risk factors (p. 100). It is in the analysis and conclusion sections ending the assessment reports, often under the headline 'Analysis and assessment' or similar, that the investigator puts forward his/her main arguments, supporting his/her recommendation that the applicants are (or are not) suitable to adopt. This is where the essence of the applicants' parenting potential is presented, and it is these sections that constitute the empirical data for our analysis.

Adoption research has shown how norms of parenthood are socially reproduced in the assessment process (Lindgren 2015; Stryker 2010). Signe Howell (2006) and Judith Modell (2002) describe how criteria for becoming an adoptive parent reflect a traditional and stereotypical family, i.e. a married couple, leading an orderly life, who are financially secure, emotionally mature and prepared to devote themselves to parenting. Given the lack of scientific tests that can prove parent suitability, when trying to ensure safe placements strong emphasis is put on the applicants' way of life, character and stability (Modell 2002; Stryker 2010). Besides our own work and that of Martine Noordegraaf and colleagues (2009), there are very few systematic studies of how various criteria for parent suitability are actually played out in assessment reports that lay the ground for the exercise of public authority and present prospective parents to sending countries. In the present study, we therefore examine, in detail, how parent suitability is displayed in the concluding arguments for granting applicants consent to adopt. The study is guided by questions concerning what assessment topics are made relevant, by what rhetorical means applicants are construed as suited to parenthood and, thus, what the concept of suitability entails in adoption assessment practices.

\section{Data and method}

\section{Data}

The present study is part of a broader project on assessment of adoption applicants in the Swedish social services. Data collection was performed in cooperation with the two largest adoption agencies in Sweden in 2012. With their assistance, letters were sent to all of their clients who had been granted consent to adopt between 2009 and 2012, requesting permission to access and use their assessment reports for research purposes. Twenty-five per cent of 
those contacted gave their informed consent. A total of 120 reports from one of the years (2011) were photocopied by the agencies, and read through and anonymized by the researchers. Fourteen reports were excluded because they were incomplete, resulting in a total sample of 106 assessment reports. As both agencies operated on a national level, the sample includes assessment reports from 62 social services units in 52 municipalities around Sweden.

\section{Analysis}

The 106 reports were scanned, transformed into digital text files, read through and corrected in accordance with the photocopies, and finally imported to a data analysis software program, NVivo, to be coded and analysed. They were then analysed thematically (Braun \& Clarke 2006; Braun et al. 2014). For the present study we, the two researchers, have analysed the concluding sections of all reports, which comprised between $3.7 \%$ and $31.1 \%$ of the total number of characters. After several joint sessions of reading and rereading the report conclusions, initial codes for assessment topics were generated (see Table 1 for a list and the prevalence of such topics). Together we established rules and descriptions for each code. One of us performed the NVivo coding according to these rules, the other worked through the other's coding to identify eventual inconsistencies, and together we discussed cases of doubt, refined the code rules and made adjustments to the coding. In the next stage of the analysis, we listed words and phrases that recurred in the descriptions of the applicants, their relationships and lives under each assessment topic. In some cases, we also performed word counts. We then proceeded to collate often-used words in the descriptions of the applicants into themes, while simultaneously being observant of language use indicating, for instance, implicit causal links between certain experiences or qualities and parent suitability, which served to balance descriptions of the applicants or to rhetorically handle any potential risk factors. We also looked for descriptions that were not present in the report conclusions. Throughout the analysis, we compared the wordings in the report conclusions with those in the adoption assessment handbook.

\section{Results}

\section{Assessment topics}

In the analysis of report conclusions, the following assessment topics were identified.

Table 1. Assessment topics in report conclusions

\begin{tabular}{|l|l|l|}
\hline Assessment topics & In number of reports (of 106) & In percentage of reports \\
\hline Couple relationship & 93 & 88 \\
\hline Social network & 92 & 87 \\
\hline Decision to adopt & 89 & 84 \\
\hline Financial situation & 86 & 81 \\
\hline Personal characteristics & 83 & 78 \\
\hline Knowledge about and insight into adoption & 82 & 77 \\
\hline Work and education & 77 & 73 \\
\hline Housing & 71 & 67 \\
\hline Experience of and knowledge about children & 53 & 50 \\
\hline Health & 46 & 43 \\
\hline Parenting performance & 40 & 38 \\
\hline View on and plan for parenthood & 39 & 37 \\
\hline Background and childhood & 34 & 32 \\
\hline Life circumstances & 28 & 26 \\
\hline Age & 24 & 23 \\
\hline
\end{tabular}




\begin{tabular}{|l|l|l|}
\hline Hobbies and leisure & 23 & 22 \\
\hline Family circumstances & 20 & 19 \\
\hline Difficulties and losses & 14 & 13 \\
\hline Beliefs and religion & 8 & 7 \\
\hline
\end{tabular}

The assessment topics in the report conclusions largely mirror the topics that are specified in the assessment handbook. However, whereas some topics - such as the couple relationship, the social network, the decision to adopt and the financial situation - could be coded at 80 per cent or more of the report conclusions, other topics were coded in only a few. In the following, we will examine what is said about the applicants in relation to the various assessment topics and how they are portrayed as suitable for adoptive parenthood.

\section{Knowledge about and insight into adoption and decision to adopt}

One of the most central assessment areas stipulated in the handbook (NBHW 2009) concerns the applicants' knowledge about and insight into adoption. In accordance with this requirement, report conclusions contain information about how knowledge has been gained, what it involves more specifically, and how the applicants reflect on it, as in the following excerpt:

Through the preparatory course for adopters, the spouses have gained experience and knowledge of the implications of adoption. Both spouses understand that adoptive children require a great deal of care and they are prepared to meet these needs by one of them staying at home during the first years. (A1)

Participation in the mandatory preparatory course is frequently mentioned as a source of knowledge. Applicants are reported to realize that adoption is a lifelong commitment and to understand that adopted children may have certain difficulties related to early losses or traumas and specific needs in relation to care, physical closeness, communication and attachment, as well as to be aware of the significance of the need to know one's origins. Further, report conclusions state that the applicants, as a consequence of their insights, are prepared to support the child, for example by planning for a longer period of parental leave or by encouraging the child to take an interest in her/his origins. When reflecting on these matters, applicants are described as sensible, open and realistic.

The applicants' decision to adopt, how they arrived at that decision and what their motives are, are commented on in 89 report conclusions. Comments convey that the decision was well considered, that both spouses are committed to the decision and see adoption as a satisfactory alternative to having children through conception. Not surprisingly, the motive most commonly mentioned is the applicants' wish for a child in combination with their involuntary biological childlessness. For applicants who are not childless, however, their own longing for an additional child does not necessarily constitute the primary motive. What is referred to in these report conclusions as the motive for adoption is that they want a sibling for their first child, explicitly or implicitly promoting the idea that it is beneficial for children to grow up with siblings. To justify such a motive, it is stated that the older child is now emotionally secure enough with her/his new parents to be able to handle the arrival of a sibling and that the applicants have the capacity to care for an additional child.

\section{Experience of children, views on parenthood and parenting performance}

The assessment of adoption applicants most often implies assessing their potential as parents. The handbook recognizes that adoption applicants may have little previous experience of 
children, but advises social workers that "if ... they [the applicants] work with children, this might well be worth highlighting in the assessment report” (NBHW 2009, p. 54). This is an interesting formulation, because it constitutes a recommendation for the social worker concerning not only what to assess, but also what to highlight in the report for future readers, thereby making explicit the assessment report's element of argumentation, which serves to convince a reader of the applicants' suitability as adopters.

Fifty-three of the report conclusions contain short accounts of the applicants' previous experiences and knowledge of children, based mostly on minding the children of siblings and friends. Accounts like these are used to demonstrate that the applicants take an interest in children, that they can be expected to have realistic views on what it is like to care for a child, that they are trusted by other parents with the care of their children, and sometimes also that they are well liked by children. In 39 of the report conclusions, the applicants' views on and plans for parenthood are also commented on. Applicants are said to have expressed, for example, that they are well prepared to become parents and ready to offer a child love, care and security. Married couples are reported to be united in their values as well as their views on child rearing.

In the 47 cases in which applicants already had children, the social worker has had the opportunity to actually investigate the applicants' performance as parents (Lindgren 2015). Consequently, 40 of the report conclusions contain social workers' own judgements, statements about what the applicants themselves have said and what external 'experts', such as pre-school teachers, have reported. Applicants who already have children are portrayed as happy, proud, open, warm, involved, responsible, mature, loving and caring parents, and the relationship between parents and child as deep, close, secure, stable, warm, natural and selfevident.

Furthermore, the applicants' child/children are characterized as happy, positive, well adjusted, secure, harmonious, social, active, curious, well developed, and empathetic. For example, the daughter of a married couple seeking to adopt again is described as:

\footnotetext{
...a happy and positive girl who easily finds things to do, who can stand up for herself and at the same time be empathetic and sensitive towards others. She is socially competent and the other children in pre-school like her. (A46)
}

Statements like this effectively communicate, without mentioning the applicants, that they are suitable for adoptive parenthood. It goes without saying that a happy, well-developed, secure and social child has good parents. Consequently, statements portraying the applicants as happy, loving and dedicated parents, the parent-child relationship as stable and secure and the child as harmonious and well developed contribute to a presentation of applicants as suitable parents.

\section{Health and age}

The handbook requires that special attention be paid to the applicants' health status and states that it is imperative "to avoid placements in families where illness or disability make it difficult for parents to meet their children's need for secure attachment, stability, continuity, closeness, care, safety and stimulation" (NBHW 2009, p. 65; italics in original). The social worker does not arrange any medical examinations and is not required to use any specific test instruments in order to evaluate the mental health of applicants. Instead, applicants are requested to submit a general medical certificate. If the social worker has doubts about the 
applicants' physical or mental health, an additional certificate from a specialist doctor or psychologist is required. Further, the handbook emphasizes that the ability to perform as a parent should last for many years and therefore states that there must be reasonable grounds for granting applicants older than 42 years consent to adopt.

Despite the handbook's emphasis on health and age, far from all report conclusions contain comments on these issues (health in 54 reports, age in 29). Comments on health are generally rather short, and mental health is rarely mentioned explicitly. The few comments on age are also rarely more than a short statement concerning the applicants' respective ages or years of birth. A possible interpretation of this relative absence is that applicants' good health and appropriate age are self-evident and therefore need not be mentioned.

In ten report conclusions, ill health or health problems are mentioned. The high age of an applicant is mentioned five times, like in the following example:

Both B's and M's age exceed the age recommended by the legislator. --- The physical and mental health status of $\mathrm{B}$ and $\mathrm{M}$ are so good that the assessing social worker estimates that they, despite their high age, will be able to give an additional child security and care for many years. (A83)

In none of the cases, however, is poor health or high age described as a problem. Instead they are mentioned, but rhetorically inactivated as risk factors, like above, with the aid of statements that affirm that age does not affect the applicants’ parenting abilities.

\section{Personal characteristics}

Another assessment topic that concerns the applicants' qualities as persons is their personal characteristics and personality. A review of the characteristics ascribed to applicants shows a varied, yet one-sidedly positive, picture.

Figure 1. Examples of personal characteristics ascribed to applicants in report conclusions

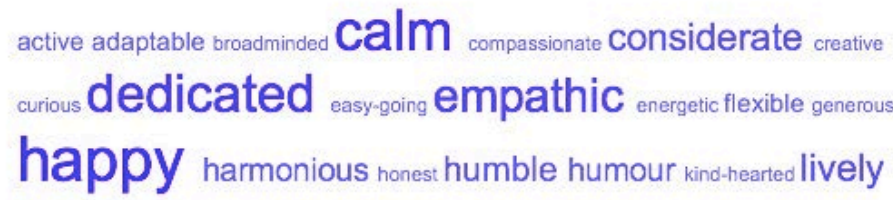

loving mature nice open osdery anom positive reflective respectur responsible

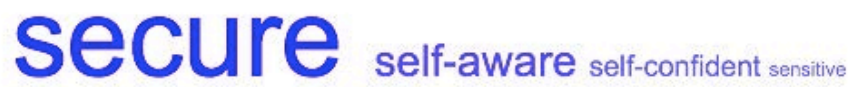

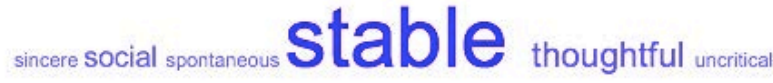


Given that more than one hundred personal traits and competences are put forward, one may conclude that the reports present quite a diverse picture of what distinguishes suitable parents. However, with very few exceptions (e.g., uncritical), these attributes all have positive connotations and, hence, the image of suitable parents is rather homogenous. This becomes even more evident when analysing further what attributes are emphasized and how. The following excerpt illustrates two clusters of characteristics ascribed to applicants:

During the period of assessment, the investigators have got to know $\mathrm{H}$ and $\mathrm{F}$ as open, happy and positive people. They are also quiet, orderly and responsible [...]. (B15)

Applicants are described as open, happy and positive, like in the excerpt, and also as active, welcoming and easy to get to know. Such descriptions portray them as outgoing and social, as people who live an active life and enjoy meeting others. This image is, however, balanced by them being described as quiet, orderly and responsible, like in the excerpt, and as responsible, mature, secure and stable. Rhetorically, these characterizations serve to create a balanced and nuanced image of prospective parents, as happy and open yet not overly outgoing and social, and as responsible and calm yet not passive or boring. In line with this is the characterization of applicants as warm, empathic and considerate. These are emotional characteristics that display both self-confidence and an interest in others. Consequently, reports describe prospective parents as happy and outgoing as well as mature and secure, and as having what this combination enables, namely emotional warmth and empathy towards others.

Two other clusters of characteristics, which serve to produce an image of balanced personalities, relate to the issue of applicants' self-image.

They are nice, mature and thoughtful and good at reflecting on themselves, life and parenting. Furthermore, they are secure and stable people with high self-esteem. (A65)

Prospective parents are described as having high self-esteem, like in the last sentence above, or self-confidence, self-reliance and integrity. Complementing this are descriptions of them as good at reflecting on themselves, like in the first sentence above, and as having selfknowledge or self-distance and being humble. Again, a balanced mixture of characteristics is ascribed to prospective parents: They are self-confident yet not self-righteous; they are selfreflexive yet not overly self-critical. This also corresponds with the handbook, which argues that self-esteem and a capacity for reflection are important qualities for adoptive parenthood (NBHW 2009).

The linguistic constructions in the excerpts above, with also and furthermore as adverbial conjunctions, make explicit how applicants are ascribed perfectly balanced personalities: happy and outgoing but also mature and responsible, self-confident but also self-reflexive. This is how applicants are portrayed as suited for parenthood, and the reports thereby neatly produce precisely the adoptive parents called for in the assessment guidelines, i.e. parents with a "healthy sense of self-reliance" and "emotional stability", who show "openness, sensitivity and responsiveness” (NBHW 2009, pp. 68, 70).

\section{Background and childhood}

The applicants' childhood is mentioned in 34 report conclusions. A relevant question concerns the ways in which the applicants' childhoods are made relevant in the concluding 
analysis of their suitability as adopters. The handbook's claims that "the way parents care for their children depends on how they themselves were parented when they were infants" and that "applicants' descriptions of their childhood and upbringing, relationships with parents, siblings and other significant carers are essential parts of the assessment" constitute part of the explanation (NBHW 2009, p. 72). However, whereas the handbook ascribes importance to childhood experiences as part of an assessment of "applicants' own attachment history" and its importance "for the conclusions as to their suitability to adopt" (NBHW 2009, p.72), there is no mention of attachment in the report conclusions.

This does not mean, however, that report conclusions are not influenced by the significance ascribed to attachment. In characterizations of applicants' childhoods, one of the most frequently used words is secure (23). Other words that are used are stable, loving and harmonious. Secure is also the term used in attachment theory to indicate an attachment style that is said to provide the best prerequisite for successful parenting (Ainsworth et al. 1978). In the reports, a causal link is drawn between a secure upbringing and applicants' parenting capacity, but it is drawn without explicit reference to attachment theory, as illustrated by the following excerpt.

Both J and C have grown up with well-functioning and good parents. That has given them security, self-esteem and sound values, which give them a good foundation to stand on when they themselves become parents. (A17)

One discursive effect of such a causal link is the understanding that a certain kind of childhood - secure, stable, loving - better prepares people for parenting than other kinds of childhoods do. Other features of this kind of childhood that are mentioned in the report conclusions include: growing up with both parents, enjoying school, having many friends, ordinary without any major setbacks or conflicts, parents who have high expectations for their children, but without any pressure, stimulating experiences, an enriching leisure time, growing up in a Christian environment, playing with a big brother, spending time in a summer house, travelling abroad, being seen and confirmed as a child, surrounded by relatives and present parents. In the few cases in which the divorce of one of the applicant's parents is mentioned, the event is rhetorically dealt with by ensuring that it has not had a serious impact on the applicants' childhoods, while clearly marking the separation as a potential matter of concern: despite the parents' divorce... and even though both $R$ and $V$ have parents who are divorced... (our underlining).

\section{Couple relationship}

Other areas of assessment, in addition to the applicants' individual characteristics and qualities, concern their relationships and lives, including characterizations of the relationship, accounts of how the couple had met and how long they had known each other or been married, accounts of how the couple interacts and feels and how they describe each other.

The adjectives most often used to describe the couple's relationship are stable (67), loving (46) - often in precisely this combination - and respectful (27). This corresponds well with what is stated in the handbook about couple relationships: "Their relationship needs to be stable so that it can withstand the possible strain and challenges involved in parenting an adopted child" and it "must be loving and characterised by mutual respect, so that they can focus on their child without being preoccupied with relationship problems" (NBHW 2009, p. 85; our italics). A series of other words have similar rhetorical effects. Couple relationships are described as secure, long, long lasting, sustainable, mature, well-functioning, and strong 
as well as close, warm, harmonious and trusting. They are further described as being marked by joy, deep companionship, responsiveness, honesty and deep friendship.

It is hardly surprising that the words used to characterize the relationships of applicants that are granted consent to adopt are exclusively positive. Of all available positive adjectives that may be used to characterize a couple relationship, however, some are used far less often than others. Only one marriage is referred to as happy. Lively is another adjective that is used only once, and no relationship is described as passionate, which would perhaps have indicated that the applicants are preoccupied with their relationship and each other in a way that leaves little room for the parenting task.

Hence, what is said about the couple relationships in the report conclusions serves to portray relationships as stable and steady. The spouses can be expected to stay together, which means that the child will be spared the experience of a divorce and of parents who do not live together. A steady relationship, however, also means that there is no risk of the applicants' energy and attention being stolen away from their parenting task.

One of the assessment topics that were coded in only a small number of report conclusions (14) was 'Difficulties and losses'. All of these concerned the involuntary childlessness that the couple had experienced. The accounts served to indicate that their relationship was strong enough to survive difficulties and if anything had deepened through the experience.

\section{Social network}

Comments on the applicants' social network concern their relationships with family and friends, and attitudes within the network towards an adoption:

The family has a warm relationship with the immediate family and a stable social network.

Relatives and friends are involved in and positive about the couple's adoption plans. (A1)

Relationships are described as warm and good, and the network as stable, rich, secure, wide and well-functioning. Such descriptions communicate that applicants are part of a social community and hence not isolated. They indicate a 'normal' social life. It is also pointed out that the network includes many children, which implies that an adopted child will have friends and that the parents' social life will be adapted to the children's needs and interests. Regarding the attitude within the network towards the planned adoption, it is also stated that relatives and friends are willing not only to offer advice and support, but also to provide practical help in the family's everyday life.

All in all, these descriptions effectively communicate that the risk factors listed in the assessment guidelines, such as isolation, weak relationships with family and friends and negative attitudes towards adoption (NBHW, 2009), do not apply to the applicants in question. They also make evident what characterizes suitable adoptive parents: They have a rich and child-friendly social life as well as supportive family and friends ready to step in when needed.

\section{Life situation}

Assessments of the applicants' suitability as parents also concern the lives they live, and report conclusions contain general information about family members, summary statements characterizing their circumstances or life situation, and more elaborated information about economy, employment, housing and hobbies. 
The applicants' financial situation, like their life circumstances in general, is characterized as good, stable, secure and well-organized. Additional information about income, property and economic margins indicates that the applicants in fact have financial resources, and statements about savings, insurances and mutual economic responsibility communicate that they are able to plan for and manage their household economy. Statements related to employment describe the applicants' employment conditions as permanent, secure and wellpaid and indicate that they have responsible and stimulating jobs that they appreciate. Working conditions are described as flexible, which indicates that they allow for parental leave and part-time work. Overall, statements about work communicate that applicants have good jobs that they enjoy, but jobs that will not stand in the way of them being dedicated parents.

The applicants' housing is also commented on, and the following excerpt illustrates what is put forward:

The family lives in a nice row house in X-town. The neighbourhood is child-friendly, with childcare, schools, public transportation, and close access to nature. (A58)

Examples of words used to signal a positive judgement of the applicants' home, like nice above, are spacious, neat, airy, modern, elegant, homey and beautiful. The area in which the applicants live is also described, and here the keyword is child-friendly. Three different characteristics constituting a child-friendly area are emphasized: i) there are preschools, schools, health care institutions and other kinds of public services, ii) there are woods, fields, green areas, playgrounds, recreational areas and room for outside activities, and iii) there are many families with children. The assessment of applicants' housing hence communicates that a child will have a nice home in a neither isolated nor overly busy neighbourhood, where she/he will have lots of fresh air and friends.

Concerning their hobbies, applicants are reported to engage in cultural activities (photography, going to museums or the theatre, playing or listening to music, reading), outdoor activities (taking walks, fishing, camping, hunting, bird-watching) as well as in working out, travelling, cooking, shopping and spending time with friends. Accompanying descriptions of how the applicants spend their time are statements indicating that they live an active, rich and sound life and that they have mutual and varied hobbies. Accordingly, information about hobbies communicates that applicants are active people, that they like doing things together, but that none of their hobbies takes up all of their time. Their life outside work is rich but balanced, thus leaving room for a child. Interestingly, some activities are never mentioned. No applicants are said to watch television in their spare time or have an interest in fashion or beauty.

Overall, the characterization of applicants' life situation rhetorically accomplishes, we would argue, two different things. Obviously, it serves to demonstrate that the applicants meet the requirements explicitly stated in the handbook, i.e. that they have no practical problems that would "impede applicant's wholehearted commitment to an adopted child" (NBHW 2009, pp. 90-91). It also, however, produces an image of them as diligent and conscientious citizens who go to work, pay their bills and have their life in order. Everything is in balance: their working hours, their finances, and even the community in which they live.

\section{Weighing up the facts?}


In relation to the social worker's recommendation in the assessment report, the handbook states that "all the factors indicating suitability or unsuitability must be included, in order to present all the information which might be necessary to reach a correct decision at a subsequent court hearing” (NBHW 2009, p 107). Social workers are hence expected to include resources as well as risk factors in the report conclusion. In the 106 report conclusions, however, the word 'risk factor' is not used once.

Even after a broader search for anything that could be interpreted as something unfavourable for the applicants, no more than 23 report conclusions were identified. Fifteen of these concern health or age and have been discussed previously. The remaining eight potential risk factors that have been identified include unemployment (2), married recently (1), an uncritical personality (1), single-parent status (1), single parent with ill child (1), many children in the family (1) and having grown up with a mentally ill mother (1). As in the case of health problems and high age, the unemployment of two different applicants (both female) is mentioned, but not treated as a risk factor or even a problem.

The fact that risk factors do not constitute a prominent feature of the report conclusions supports the interpretation of this report section as a summary of the arguments that support the social worker's recommendation, rather than a weighing-up of all the facts (cf.

Noordegraaf et al. 2008b).

\section{Concluding discussion}

As we have argued, the conclusions of adoption assessment reports constitute the essence of the social worker's argumentation for the recommendation that s/he submits to the municipal social welfare committee to either grant or deny the applicants consent to adopt. Given our data selection, which includes only reports on applicants who have been granted consent to adopt, our research question has concerned how the adoption applicants' suitability has been displayed in the assessment report conclusions. In our concluding discussion, we will primarily highlight two aspects of our analysis: the role of the handbook and what implications the fact that what can be assessed is the applicants' potential as parents has for the content of the report conclusions.

The ways in which applicants, their relationships and lives are described and the qualities they are ascribed have a strong resemblance to the content of the handbook (cf. Modell 2002). Because the assessment process serves to examine whether the applicants have the qualities and resources needed to be suitable adoptive parents and because the handbook specifies what these qualities are, this is perhaps hardly surprising. To be granted consent to adopt, applicants should display precisely the qualities and resources listed in the handbook. Hence, if the social worker's assessment report is to support a recommendation to grant consent for a particular applicant or couple, it should demonstrate that the applicants have the qualities and resources specified in the handbook. This means that the handbook not only serves as a checklist and defines the valid arguments, but also provides a catalogue of arguments to use. As a result, it helps in defining good parenthood, but it also outlines a way of life that is associated with good parenthood.

Furthermore, our analysis of the concluding arguments for granting consent to adopt shows how the portrayal of applicants relates to three layers of suitability: one concerning factors specific to the task of parenting an adopted child, such as the applicants' knowledge of 
adoption and readiness to meet the specific needs of an adopted child; another concerning factors related to parenting in general, such as the applicants' experience of children and views on parenthood and child rearing; and a third concerning factors related to the applicants and their life in general, such as housing, finances and hobbies. The latter is not necessarily associated with the task of parenting, but construed as prerequisites that enable someone to be a good parent by living the kind of life that allows him/her to prioritize parenthood over (all) other aspects of life (cf. Modell 2002; Stryker 2010). Hence, it is not sufficient to want to adopt for the right reason, to have knowledge about the needs of adoptive children, and to be healthy and not too old. Applicants are also described as having a balanced personality, suitable to the task of parenting. They had a secure childhood and if they are a couple, their relationship is stable and loving, but not passionate - hence will not steal their attention away from the parenting task. Finally, they have financial resources and are able to manage them, have a good job, are well paid in a secure occupation that they enjoy, but are not preoccupied with. They have a nice home in a child-friendly area. Overall, the most often used words in the report conclusions, referring to personalities, relationships, childhoods, jobs as well as financial situations, are 'stable' and 'secure'.

In its introduction, the handbook states that "perfection is not what it is all about" (NBHW 2009, p. 10). It could be argued, however, that normality is what it is all about (cf. Noordegraaf 2009). Modell (2002) has argued that assessment criteria reflect mainstream, middle-class values and narrow the meaning of suitability. Her characterization of ideal adoptive parents is also relevant in a Swedish context: They are stable and steady; they "show no unusual traits and make no outlandish requests" (p. 134). Despite the handbook's instruction that the social worker's analysis and conclusions should include resources as well as risk factors (NBHW 2009), there is little mention of risk factors. Instead applicants are portrayed as having a life free from distractions such as uncertain short-term employment or high-profile careers, passionate marriages, absorbing hobbies, complicated relationships to parents or siblings and unconventional childhoods. This does not mean that adoptive parents cannot have these things in their lives. Rather it means that suitability as an adoptive parent is displayed in the report conclusions through descriptions of lives that are conventional and orderly, but also average in the sense that there is neither too little nor too much of anything.

\section{Limitations}

The present study does not aim to investigate the assessment of applicants who are not considered suitable for adoptive parenthood, although such an investigation would have been relevant. To conduct such a study, one would need to scan more than 200 local archives to find the rare cases (approximately 1.5\%) in which an application is rejected, and that was not feasible in the present project. Furthermore, applicants who realize that they may not be granted consent to adopt may choose to terminate the assessment process before it is completed (NBHW 2009). A study of such cases would thus require a design that includes data from assessment sessions and/or interviews with social workers. Consequently, the present study focuses on the specific question it poses: What must be said about an individual or a couple in order for her/them to be seen as a suitable adoptive parent?

\section{Acknowledgements}

This work was supported by grants from the Swedish Research Council (70201801) and the Swedish Research Council for Health, Working Life and Welfare (2015-00542).

\section{Ethical approval}

The research procedure was independently reviewed and approved by the Regional Ethical Review Board, Linköping, Sweden (3510180000). 


\section{References}

Ainsworth, M.D.S., Blehar, M. C., Waters, E., \& Wall, S. (1978). Patterns of attachment: A psychological study of the strange situation. Earlbaum, Hillsdale, NJ.

Barnens Vänner (2014) "Innehållet i medgivandeutredningar", Adoption. Barnens Vänner Internationell Adoptionsförenings medlemstidning 2014(1), 8.

Caputo, V. (2007) She's from a 'Good Family'. Performing childhood and motherhood in a Canadian private school setting, Childhood 14 (2), 173-192.

Braun, V. \& Clarke, V. (2006) Using thematic analysis in psychology, Qualitative Research in Psychology 3 (2), 77-101.

Braun, V., Clarke V. \& Terry, G. (2014) Thematic analysis. In: Qualitative research in clinical and health psychology (eds P. Rohleder \& A. Lyons), pp. 95-113. Palgrave MacMillan, Basingstoke.

Dermott, E. \& Seymour, J. (2011) Displaying families. A new concept for the sociology of family life. Palgrave Macmillan, Basingstoke.

Hall C., Slembrouck, S. \& Sarangi, S. (2006) Language practices in social work. Routledge, London.

Harman, V. \& Cappellini, B. (2015) Mothers on display. Lunchboxes, social class and moral accountability, Sociology 49 (4), 764-781.

Hicks, S. (2000) 'Good lesbian, bad lesbian...': regulating heterosexuality in fostering and adoption assessments, Child and Family Social Work 5 (2), 157-168.

Holland, S. (1999) Discourses of decision making in child protection: conducting comprehensive assessments in Britain, International Journal of Social Welfare 8 (4), 277287.

Howell, S. (2006) The Kinning of Foreigners. Berghahn Books, New York.

Hydén, L-C. (1997) The institutional narrative as drama. In: The construction of professional discourse (eds B-L. Gunnarsson, P. Linell \& B. Nordberg), pp. 245-264. Longman, London.

Finch, J. (2007) Displaying families, Sociology 41 (1), 65-81.

Lind J. (2008) The best interest of the child as an argument in assessments of parent potential in Sweden, International Journal of Law, Policy and the Family 22 (1), 1-21.

Lindgren, C. (2015) Ideals of parenting and childhood in the contact zone of intercountry adoption: Assessment of second-time adoption applicants in Sweden, Childhood 22 (4), 474489. 
Modell, J. (2002) A sealed and secret kinship. The culture of policies and practices in American adoption. Berghahn Books, New York \& Oxford.

National Board of Health and Welfare (2009) Adoption. Handbook for the Swedish social services. Edita Västra Aros, Västerås.

Noordegraaf, M., van Nijnatten, C. \& Elbers, E. (2010) Assessing and displaying suitability for adoptive parenthood: a conversation analysis of relationship questions and answers, Text \& Talk 30 (3), 289-309.

Noordegraaf, M., van Nijnatten, C. \& Elbers, E. (2009) Assessing candidates for adoptive parenthood, Children and Youth Services Review 31 (1), 89-96.

Noordegraaf, M., van Nijnatten, C. \& Elbers, E. (2008a) Future talk: Hypothetical situations with prospective adoptive parents, Qualitative Social Work 7 (3), 310-329.

Noordegraaf, M., van Nijnatten, C. \& Elbers, E. (2008b) Assessing suitability for adoptive parenthood: hypothetical questions as part of ongoing conversation, Discourse Studies 10 (5), 655-672.

Stryker, R. (2010) The Road to Evergreen: Adoption, attachment therapy, and the promise of family. Cornell University Press, Ithaca. 